\title{
A Randomized Trial Comparing 2 Techniques of Balloon Kyphoplasty and Curette Use for Obtaining Vertebral Body Height Restoration and Angular-Deformity Correction in Vertebral Compression Fractures due to Osteoporosis
}

L. Bastian, F. Schils, J.B. Tillman, and G. Fueredi, on behalf of the SCORE Investigators

\section{ABSTRACT}

BACKGROUND AND PURPOSE: Vertebral compression fractures often result in pain and vertebral deformity. We compared 2 different balloon kyphoplasty techniques both using intraoperative curettage.

MATERIALS AND METHODS: Adults 50 years of age or older with osteoporosis and 1 acute VCF were randomized to undergo bilateral BKP in which the curette was used first $(n=57)$ followed by inflatable bone tamps or in which IBTs were used first, followed by curettage and a second IBT inflation $(n=55)$.

RESULTS: Mean procedure duration was 33.5 and 36.8 minutes, and fluoroscopy duration was 3.8 and 3.7 minutes for the CF and IBTF groups, respectively. Two-thirds of VCFs were wedge-shaped, and one-half had dynamic mobility. Anterior height restored postoperatively was $2.28 \mathrm{~mm}(95 \% \mathrm{Cl}, 1.49-3.08 \mathrm{~mm} ; P<.001)$ and $2.78 \mathrm{~mm}(95 \% \mathrm{Cl}, 1.89-3.66 \mathrm{~mm} ; P<.001)$ for CF and IBTF groups, representing $\sim 35 \%$ and $39 \%$ of lost height restored, but group differences were not significant $(P=.4)$. Intraoperative anterior height gain attributed to dynamic mobility was $2.96 \mathrm{~mm}(95 \% \mathrm{Cl}, 1.92-4.00 \mathrm{~mm} ; P<.001)$ and $3.05 \mathrm{~mm}(95 \% \mathrm{Cl}, 2.10-4.00 \mathrm{~mm} ; P<.001)$; additional height attributed to IBT inflation was $1.09 \mathrm{~mm}(95 \% \mathrm{Cl}, 0.77-1.41 \mathrm{~mm} ; P<.001)$ and $1.25 \mathrm{~mm}(95 \% \mathrm{Cl}, 0.68-1.82 \mathrm{~mm} ; P<.001)$, representing a $37 \%$ and $41 \%$ increase. There was no significant height loss on IBT removal and cementation. Both groups had improved pain and ambulation. Asymptomatic leakage occurred in $15 \%$ of VCFs. There was 1 nonserious device-related hematoma (IBTF group). One new clinical VCF occurred in each group, but they were not device-related.

CONCLUSIONS: Both techniques resulted in significant vertebral body height and pain improvement. Procedure and adverse event data demonstrated safe curette use in conjunction with balloon kyphoplasty procedures.

ABBREVIATIONS: $\mathrm{BKP}=$ balloon kyphoplasty; $\mathrm{CF}=$ curette-first; $\mathrm{Cl}=$ confidence interval; $\mathrm{IBT}=$ inflatable bone tamp; $\mathrm{IBTF}=\mathrm{IBT}$-first; $\mathrm{IQR}=$ interquartile range; $\mathrm{VCF}=$ vertebral compression fracture

V ertebral compression fractures are associated with vertebral deformity and pain and a decrease in a patient's mobility, function, and quality of life. ${ }^{1}$ Approximately $25 \%$ of women older than 50 years of age and $40 \%$ of women older than 80 years have a

Received March 16, 2012; accepted after revision May 25.

From the Klinikum Leverkusen (L.B.), Leverkusen, Germany; Department of Neurosurgery (F.S.), Clinique Saint Joseph, Liège, Belgium; Medtronic Spine LLC (J.B.T.), Sunnyvale, California; and Aurora Memorial Hospital of Burlington (G.F.), Burlington, Wisconsin.

Author contributions: L.B. declares primary contributions to data collection and interpretation, manuscript development, content approval, and final submission decision. F.S. declares primary contributions to data collection and interpretation, manuscript development, content approval, final submission decision. J.B.T. declares primary contributions to manuscript development, data interpretation and analysis, and content approval. G.F. declares primary contributions to data collection and interpretation, manuscript development, content approval, and final submission decision. The publication committee (L.B., F.S., and G.F.), which did not include the sponsor, approved the final version and had the final responsibility for the decision to submit the publication; however, an author from Medtronic Spine LLC (J.B.T.) contributed to data analysis and interpretation and manuscript development and content.
VCF each year ${ }^{1}$; approximately two-thirds of vertebral fractures do not come to clinical attention, ${ }^{2}$ though the effects of the associated deformity are not inconsequential. ${ }^{1}$

Balloon kyphoplasty is a minimally invasive treatment option designed to stabilize VCFs and correct angular deformity. During kyphoplasty, 2 inflatable bone tamps are placed into the vertebral body under fluoroscopic guidance. Inflation of the IBTs compacts the cancellous bone, creating a cavity within the vertebral body,

This work was supported by Medtronic Spine LLC.

The trial is posted on www.clinicaltrials.gov (NCT00810043).

Please address correspondence to Leonard Bastian, MD, Klinik für Orthopädie, Unfall-, Hand- und Wiederherstellungschirurgie, Klinikum Leverkusen gGmbH, Am Gesundheitspark 11, 51375 Leverkusen, Germany; e-mail: leonard.bastian@klinikumlev.de

- Indicates open access to non-subscribers at www.ajnr.org

Indicates article with supplemental on-line tables.

Evidence-Based Medicine Level 1.

http://dx.doi.org/10.3174/ajnr.A3363 
and pushes the endplates apart, often restoring lost height and correcting angular deformity. ${ }^{3-6}$ After the balloons are removed, the void is filled with bone cement. In 2 randomized trials, BKP was shown to provide better pain, disability, and quality-of-life outcomes than nonsurgical management for patients with osteoporosis and cancer. ${ }^{5,7,8}$

The ability to restore vertebral anatomy is affected by many factors, including patient positioning, IBT inflation and position within the vertebral body, and the presence of sclerotic bone. A curette may be used as an adjunct tool to scrape and score cancellous bone either before or after the IBTs are inflated in an attempt to disrupt sclerotic bone that may hinder vertebral body height restoration.

Currently there is limited clinical evidence regarding the use of the curette in balloon kyphoplasty procedures. The overall objective of this study was to document the relative roles of postural reduction and systematic curette use, in combination with the IBT, in obtaining vertebral body anatomy height restoration during the balloon kyphoplasty procedure.

\section{MATERIALS AND METHODS \\ Patients/Subjects}

The SCORE trial was a randomized nonblinded trial comparing 2 surgical techniques for performing balloon kyphoplasty. Patients were randomized from February 2009 through August 2010. All participants had 1 acute (with edema on MR imaging), painful, thoracic or lumbar (T5-L5) vertebral fracture due to primary or secondary osteoporosis; the acute fracture also had to have caused at least $15 \%$ height loss. In the absence of cancer or trauma (see exclusions below), the presence of a VCF is a hallmark of osteoporosis ${ }^{9}$; therefore, the decision to perform diagnostic bone mineral attenuation examinations was determined by treating physicians and was not a study requirement. Patients were allowed to have chronic fractures as long as at least 1 adjacent segment was not fractured; chronic fractures were not treated. Patients were excluded from participating if they could not undergo MR imaging or standing lateral $x$-rays; had $>1$ acute fracture; had fractures due to cancer or high-energy trauma; had a body mass index $>35$ $\mathrm{kg} / \mathrm{m}^{2}$; required procedures other than BKP for fracture stabilization; or had contraindications to BKP such as irreversible coagulopathy, known allergies to bone cement or contrast, or evidence of systemic infection or infection within the spine. Participants gave written informed consent before enrollment. The protocol and consent forms were approved by local ethics committees.

Because this study was descriptive in nature, a sample size of 120 patients was deemed adequate to obtain results for primary and secondary end points.

\section{Research Design}

Patients were randomly assigned in a 1:1 ratio to have kyphoplasty by using the IBT-first followed by curette usage and a second IBT inflation (IBT-first) or a kyphoplasty procedure where the curette was used first followed by IBT inflation (curette-first). We investigated these 2 approaches within the study design because they are standard methods used clinically. Study randomization took place in the operating room and was stratified by the presence or absence of dynamic fracture mobility when the patient was placed prone on the operating table; this assessment was made by treating physicians by using intraoperative fluoroscopy. The study was performed at 11 investigational centers in 3 countries (Belgium, Germany, and the United States).

Balloon kyphoplasty was performed by using introducer tools, inflatable bone tamps, curettes and polymethylmethacrylate bone cement, and delivery devices (all devices were manufactured by Medtronic Spine, Sunnyvale, California), by using a percutaneous, bilateral, transpedicular, or extrapedicular approach. ${ }^{10}$ The curette tip can be ratcheted $0^{\circ}, 30^{\circ}, 60^{\circ}$, and $90^{\circ}$ and locked in place for each setting. In the curette-first arm, after vertebral body access and appropriate channel creation with standard bone access systems, the curette was inserted first on 1 side to scrape the cancellous bone to establish a specific and directed path of least resistance for balloon insertion. The $30^{\circ}$ position was used first with scraping from anterior to posterior throughout the vertebral body; articulations at $60^{\circ}-90^{\circ}$ were used when possible subsequently; similar use of the curette occurred on the contralateral side. In the IBT-first group, balloons were inserted into the working channel first; on inflation, the operator may visualize irregular or undesired balloon inflation profiles or limited balloon inflation volume due to hard bone. In these cases, the curette was appropriately oriented to scrape cancellous bone in the areas hindering balloon inflation. In all cases of curettage in both treatment arms, care was taken so as not to breach the cortical bone. Most procedures were performed with the patient under general anesthesia; some patients had conscious or deep sedation with local anesthesia.

The primary end point of the study was the difference in the percentage of vertebral body height restored (anterior, medial, and posterior vertebral body measurements ${ }^{11}$ ) in each study arm as measured at discharge by using standing lateral radiographs. Secondary radiographic end points included vertebral body height restored in millimeters; kyphosis angle, defined as the angle formed by lines drawn parallel to the caudal and cranial fractured vertebral body endplates; and the local Cobb angle, defined as the angle formed by lines drawn parallel to the superior endplate of the vertebral body above and the inferior endplate of the vertebral body below. ${ }^{6}$ Clinical secondary end points included postoperative back pain relief by using a numeric rating scale that assessed current pain (scale $0-10),{ }^{12}$ ambulatory status (subjective patient questionnaire), and all adverse events. Radiographic outcomes were assessed at baseline/screening and intra- and postoperatively. Back pain and ambulation were assessed at baseline/screening and postoperatively (discharge), while adverse events were collected throughout the study through 30 days postoperatively.

Adverse events and serious adverse events were coded according to the Medical Dictionary for Regulatory Activities (http:// www.meddramsso.com). ${ }^{13}$ All adverse events and serious adverse events within 30 days were reported, as randomized. An adverse event was considered serious if it resulted in death, life-threatening injury, or permanent impairment; required intervention to prevent impairment; or required prolonged hospitalization. Site investigators reviewed and signed all case report forms, which were source-verified for $100 \%$ of the patients.

Radiographic imaging guidelines were established before study start for consistency; for pre- and postoperative images, 


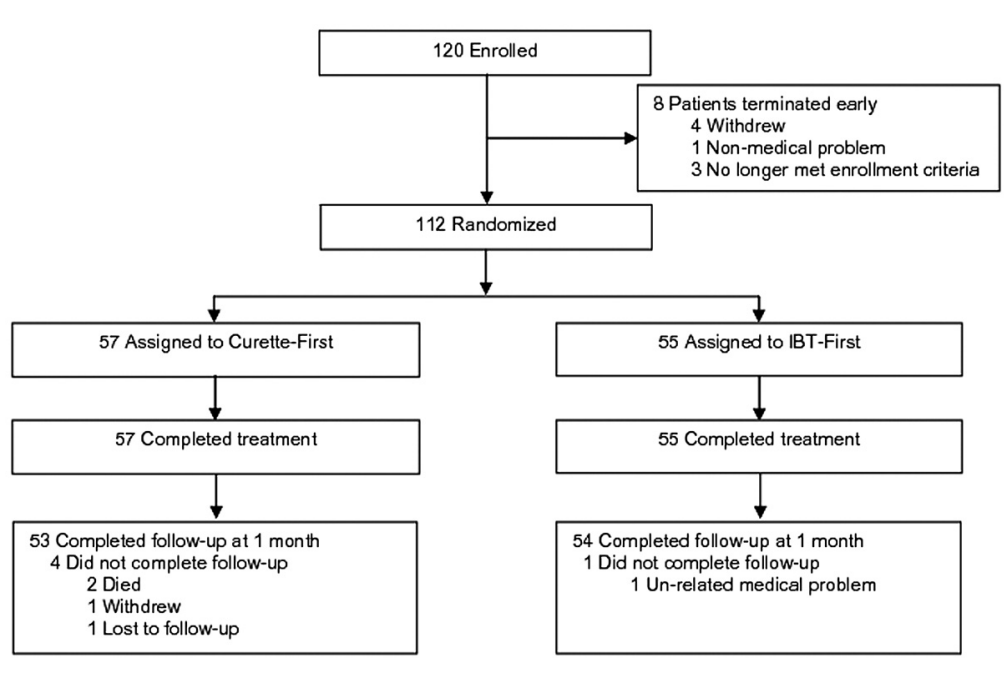

FIG 1. Patient accountability.

Table 1: Baseline patient demographics

\begin{tabular}{lcc}
\multicolumn{1}{c}{ Characteristic } & CF & IBTF \\
\hline No. of patients evaluable ${ }^{\mathrm{a}}$ & 57 & 55 \\
Age (yr) (mean) & $73.6 \pm 8.4$ & $76.0 \pm 9.4$ \\
Weight in kg (mean) & $71.0 \pm 16.2$ & $71.8 \pm 16.3$ \\
Height in cm (mean) & $162.1 \pm 8.3$ & $162.2 \pm 8.8$ \\
Female (No.) (\%) & $47(82.5)$ & $41(74.5)$ \\
Ethnicity (No.) (\%) & $55(96.5)$ & $55(100.0)$ \\
$\quad$ Caucasian & $1(1.8)$ & $0(0)$ \\
$\quad$ Hispanic & $1(1.8)$ & $0(0)$ \\
$\quad$ Middle Eastern & & \\
Smoking history (No.) (\%) & $36(63.2)$ & $36(65.5)$ \\
$\quad$ Never & $14(24.6)$ & $14(25.5)$ \\
Former & $7(12.3)$ & $5(9.1)$ \\
$\quad$ Current & $4.0(2.0,9.0)$ & $5.0(3.0,8.0)$ \\
Index fracture age (wk) (median) (IQR) & \\
Index vertebral body location (No.) (\%) & & $6(10.9)$ \\
T5-T9 & $7(12.3)$ & $37(67.3)$ \\
T10-L2 & $42(73.7)$ & $12(21.8)$ \\
$\quad$ L3-L5 & $8(14.0)$ & \\
Index fracture morphometry (No.) (\%) & & \\
Wedge & $38(66.7)$ & $34(61.8)$ \\
Crush & $4(7.0)$ & $4(7.3)$ \\
Concave & $15(26.3)$ & $17(30.9)$ \\
Prior symptomatic VCF (No.) (\%) ${ }^{\mathrm{b}}$ & & \\
0 & $44(77.2)$ & $43(78.2)$ \\
1 & $5(8.8)$ & $11(20.0)$ \\
2 & $2(3.5)$ & $1(1.8)$ \\
3 & $6(10.5)$ & $0(0)$ \\
\hline A & & \\
\hline
\end{tabular}

${ }^{a} A$ total of 120 patients enrolled. Eight patients withdrew early, did not receive surgery, and, therefore, did not receive randomization assignment.

${ }^{\mathrm{b}}$ As determined by treating physicians.

patients were in a standing position with legs straight and the shoulder against the Bucky with shoulders and hips perpendicular to it. Arms were either at a right angle to the body holding a support bar or across the chest if no bar was available. The beam and Bucky were centered at the index level to minimize parallax. A specific calibration marker, attached to a lanyard, was draped over the shoulder and positioned near the treated level. Intraoperatively, patients were placed prone with bolsters under the hips and shoulders (some patients had images obtained pre- and postbolstering) and imaged to assess postural reduction. Images were also taken after each IBT inflation step and cement placement. All spine radiographs and images were assessed centrally (Medical Metrics, Houston, Texas); an independent radiologist, blinded to treatment assignment, used quantitative morphometry ${ }^{11}$ to determine anterior, mid-, and posterior vertebral body locations by using a computer-based marking system. Vertebral body height restoration and kyphotic angulation measurements were based on the quantitative morphometry.

\section{Statistical Methods}

Results were analyzed by modified intention to treat, including all data available at baseline and follow-up from all (112) patients randomized and treated. Eight additional patients were enrolled in the study but were terminated early before the procedure; because randomization was conducted in the operating room due to stratification based on dynamic fracture mobility, these $8 \mathrm{pa}$ tients were not randomized to treatment. We used analysis of variance to analyze the continuous primary and secondary radiographic and pain end points between treatment groups; for categoric variables, between-group comparisons were assessed by using $\chi^{2}$, and, when appropriate, the Fisher exact test. A $P$ value of .05 was considered statistically significant.

\section{Role of the Funding Source}

This study was sponsored and funded by Medtronic Spine LLC, which contributed to the study design, data monitoring, statistical analysis, and reporting of results and paid for core laboratory services (Medical Metrics, Houston, Texas). All authors had complete access to data and were provided all analyses requested.

\section{RESULTS}

\section{Patient Disposition and Demographics}

Patients were enrolled between February 2009 through August 2010 and were randomized to curette-first $(n=57)$ or IBT-first ( $n=55)$ groups. Patient disposition is shown in Fig 1. Eight patients were discontinued before the planned procedure and were not randomized to treatment. Of the 112 patients who were randomized, 5 patients discontinued before 1 month.

Patients were, on average, 75 years of age, and $79 \%$ were women (Table 1). In the overall cohort, $78 \%$ of patients did not have any prior VCF. At baseline, wedge fractures were the most common type of VCF identified by investigators (64\%). Median fracture age was 4.0 and 5.0 weeks in the CF and IBTF groups, respectively. In the overall cohort, 73 of $112(65 \%)$ patients randomized had bone mineral attenuation examinations; in this subset of patients, the average $t$-score was $-1.9 \pm 1.0$.

\section{Procedure and Fracture Characteristics}

Randomization was stratified by fracture mobility and was conducted in the operating room; one-half of treated fractures had dynamic mobility observed by the treating physician when patients were placed prone with bolsters on the operating table (Table 2). Most patients were treated by using general anesthesia $(83 \%)$ and a bipedicular transpedicular approach (94\%). The 
Table 2: Procedure characteristics

\begin{tabular}{lcc}
\hline \multicolumn{1}{c}{ Procedure $^{\mathrm{a}}$} & CF & IBTF \\
\hline No. of patients treated & 57 & 55 \\
Patients with mobile fracture (No.) (\%) & $29(50.9)$ & $28(50.9)$ \\
Procedure duration (min) (mean) & $33.5 \pm 10.8$ & $36.8 \pm 12.5$ \\
Fluoroscopy duration (min) (mean) & $3.8 \pm 2.0$ & $3.7 \pm 3.3$ \\
Anesthesia & & \\
$\quad$ General & $49(86.0)$ & $44(80.0)$ \\
$\quad$ Local & $8(14.0)$ & $11(20.0)$ \\
Approach & & \\
$\quad$ Extrapedicular & $3(5.3)$ & $3(5.5)$ \\
$\quad$ Transpedicular & $54(94.7)$ & $51(92.7)$ \\
Initial IBT inflation volume (mL) & & \\
$\quad$ Left & $2.76 \pm 1.21$ & $2.52 \pm 1.38$ \\
$\quad$ Right & $2.86 \pm 1.23$ & $2.52 \pm 1.45$ \\
Initial IBT inflation pressure (PSI) & $167.3 \pm 73.0$ & $168.5 \pm 79.5$ \\
$\quad$ Left & $169.9 \pm 84.8$ & $159.5 \pm 75.9$ \\
$\quad$ Right & & \\
Final IBT inflation volume (mL) & $2.79 \pm 1.29$ & $3.00 \pm 1.48$ \\
$\quad$ Left & $2.85 \pm 1.35$ & $3.03 \pm 1.51$ \\
$\quad$ Right & & \\
Final IBT inflation pressure (PSI) & $164.1 \pm 87.3$ & $151.8 \pm 86.2$ \\
$\quad$ Left & $157.6 \pm 89.0$ & $138.6 \pm 77.5$ \\
$\quad$ Right & & \\
Final cement volume (mL) & $2.78 \pm 1.20$ & $2.94 \pm 1.16$ \\
$\quad$ Left \\
$\quad$ Right \\
Length of stay (hours) & $2.89 \pm 1.25$ & $3.00 \pm 1.16$ \\
\hline
\end{tabular}

a Thirteen patients in the curette-first group had an additional curettage and IBT inflation; 7 patients in the IBT-first group had a third IBT inflation.

mean kyphoplasty procedure duration was 33.5 and 36.8 minutes, with mean fluoroscopy durations of 3.8 and 3.7 minutes for the CF and IBTF groups, respectively. On average, final bilateral IBT inflation volumes for the CF and IBTF groups were 5.6 \pm 2.6 and $6.0 \mathrm{~mL} \pm 2.8 \mathrm{~mL}$, which were consistent with cement volumes of $5.7 \pm 2.3$ and $5.9 \pm 2.2 \mathrm{~mL}$. For the CF and IBTF groups, hospitalization duration was an average of 96.1 and 77.5 hours, respectively.

As assessed by the radiographic core laboratory, most fractures were wedge-shaped and were considered moderate or severe. Nineteen percent had a vacuum cleft present (Table 3).

\section{Primary End Point}

The primary end point of the study was height restoration assessed postoperatively by using standing lateral films. The mean baseline anterior height was $60.2 \%$ (95\% CI, 54.6\%-65.8\%) and $58.6 \%$ (95\% CI, 53.8\%-63.4\%) of adjacent normal vertebrae for the CF and IBTF groups, which was improved to $70.5 \%$ (95\% CI, $66.2 \%-74.8 \% ; P<.001)$ and $71.3 \%$ (95\% CI, 67.2\%-75.3\%; $P<$ .001 ), respectively (Fig 2). The improvement observed was not statistically significantly different between the 2 treatment groups $(P=.4)$. Similar results were found at the midvertebral measurements (Fig 2).

\section{Secondary Radiographic End Points}

At baseline, compared with normal adjacent vertebrae, the average anterior height loss of index fractures measured was -6.49 $\mathrm{mm}(95 \% \mathrm{CI},-7.51$ to $-5.47 \mathrm{~mm})$ and $-7.13 \mathrm{~mm}(95 \% \mathrm{CI}$, -8.21 to $-6.06 \mathrm{~mm}$ ) for the CF and IBTF groups, respectively. Compared with the preoperative standing assessment, the intraoperative anterior height gain, attributed to unloading the spine
Table 3: Fracture characteristics ${ }^{\mathrm{a}}$

\begin{tabular}{|c|c|c|}
\hline Preoperative Fracture Evaluation & CF & IBTF \\
\hline No. of patients treated & 57 & 55 \\
\hline No. of fractures evaluable & 56 & 54 \\
\hline \multicolumn{3}{|l|}{ Fracture type } \\
\hline Wedge & $47(83.9)$ & $44(81.5)$ \\
\hline Biconcave & 9 (16.1) & $10(18.5)$ \\
\hline Crush & $0(0)$ & $0(0)$ \\
\hline \multicolumn{3}{|l|}{ Severity of fracture } \\
\hline Slight & $13(23.2)$ & $10(18.5)$ \\
\hline Moderate & $21(37.5)$ & $23(42.6)$ \\
\hline Severe & $22(39.3)$ & $21(38.9)$ \\
\hline \multicolumn{3}{|l|}{ Vacuum cleft } \\
\hline Absent & $43(76.8)$ & $46(85.2)$ \\
\hline Present & $13(23.2)$ & $8(14.8)$ \\
\hline \multicolumn{3}{|l|}{ Intraoperative evaluation } \\
\hline No. of fractures evaluable & 55 & 51 \\
\hline Cement leakage absent & $46(83.6)$ & $44(86.3)$ \\
\hline Cement leakage present & $9(16.4)$ & 7 (13.7) \\
\hline Disk & 8 & 6 \\
\hline Epidural/foraminal & 1 & 0 \\
\hline Paraspinal & 2 & 1 \\
\hline Vascular & 2 & 1 \\
\hline$>15 \mathrm{~mm}$ & 1 & 0 \\
\hline
\end{tabular}

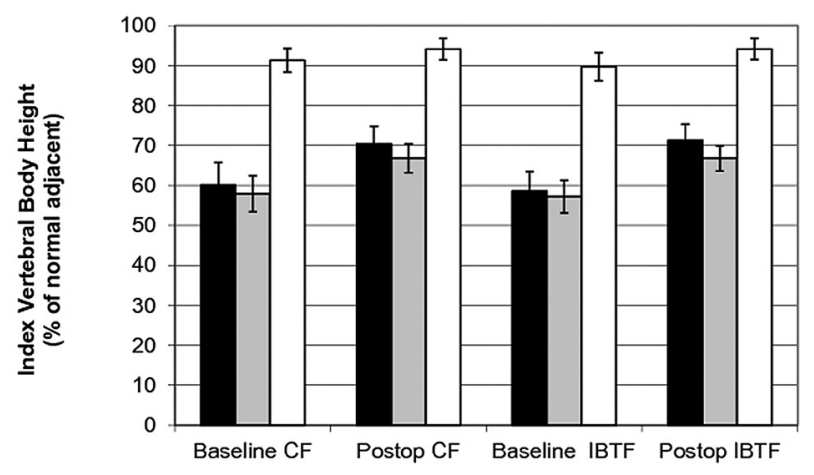

FIG 2. Primary end point of absolute height restored at index vertebrae as a percentage of adjacent normal vertebrae. Group means and $95 \%$ confidence intervals are shown for measurements at the posterior, anterior, and midpoint of index vertebral bodies for each group at baseline and at 48 hours postoperatively by using standing lateral x-ray films.

and providing postural reduction, was $2.96 \mathrm{~mm}$ (95\% CI, $1.92-$ $4.00 \mathrm{~mm} ; P<.001)$ and $3.05 \mathrm{~mm}$ (95\% CI, 2.10-4.00 mm; $P<$ .001 ) for the CF and IBTF groups, respectively (Fig 3); however, the improvement observed between groups was not statistically significantly different $(P=.9)$. The additional benefit in intraoperative height gain attributed to the first IBT inflation was 1.09 $\mathrm{mm}(95 \% \mathrm{CI}, 0.77-1.41 \mathrm{~mm} ; P<.001)$ in the CF group and 1.25 $\mathrm{mm}(95 \% \mathrm{CI}, 0.68-1.82 \mathrm{~mm} ; P<.001)$ in the IBTF group, representing a $37 \%$ and $41 \%$ increase in the anterior measurement over postural reduction; there was no significant height loss on IBT removal and cement placement (Fig 3). The final preoperative-to-postoperative anterior height improvement was $2.28 \mathrm{~mm}$ (95\% CI, 1.49-3.08 mm; $P<.001)$ and $2.78 \mathrm{~mm}$ (95\% CI, 1.89$3.66 \mathrm{~mm} ; P<.001$ ) for the CF and IBTF groups (Fig 3), representing $\sim 35 \%$ and $39 \%$ of lost height restored. Differences were not statistically different between groups in the anterior improve- 
$\mathrm{CF}$

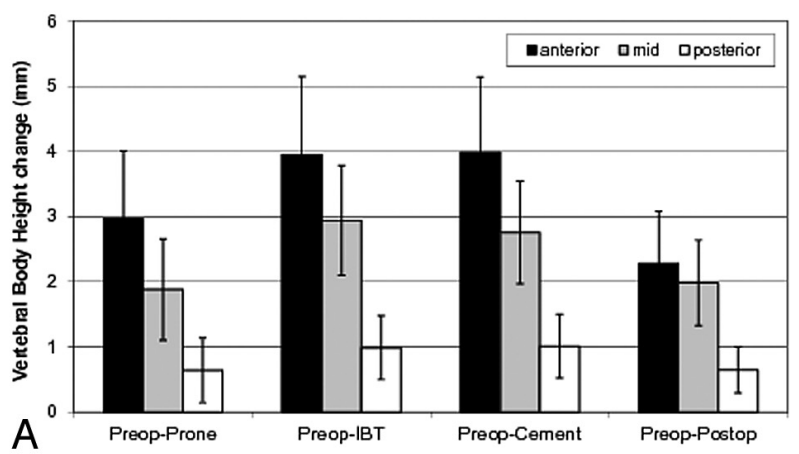

IBTF

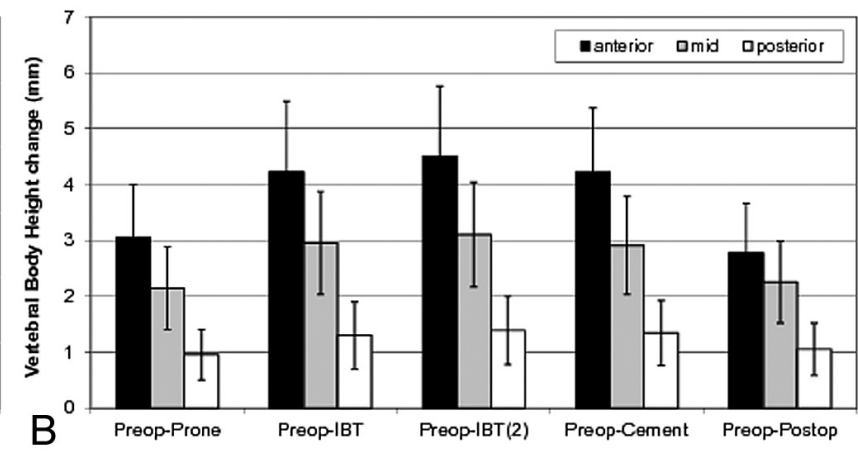

FIG 3. Index vertebral body height gain in millimeters. CF $(A)$ and IBTF $(B)$ group means and $95 \%$ confidence intervals are shown for vertebral body height improvement (compared with preoperative) in millimeters, measured at the posterior, anterior, and midpoint of index vertebral bodies after prone positioning (postural reduction), IBT inflation, cementation, and postoperative steps. Preoperative and postoperative assessments used standing lateral $x$-rays, and intraoperative assessments used lateral fluoroscopic images.
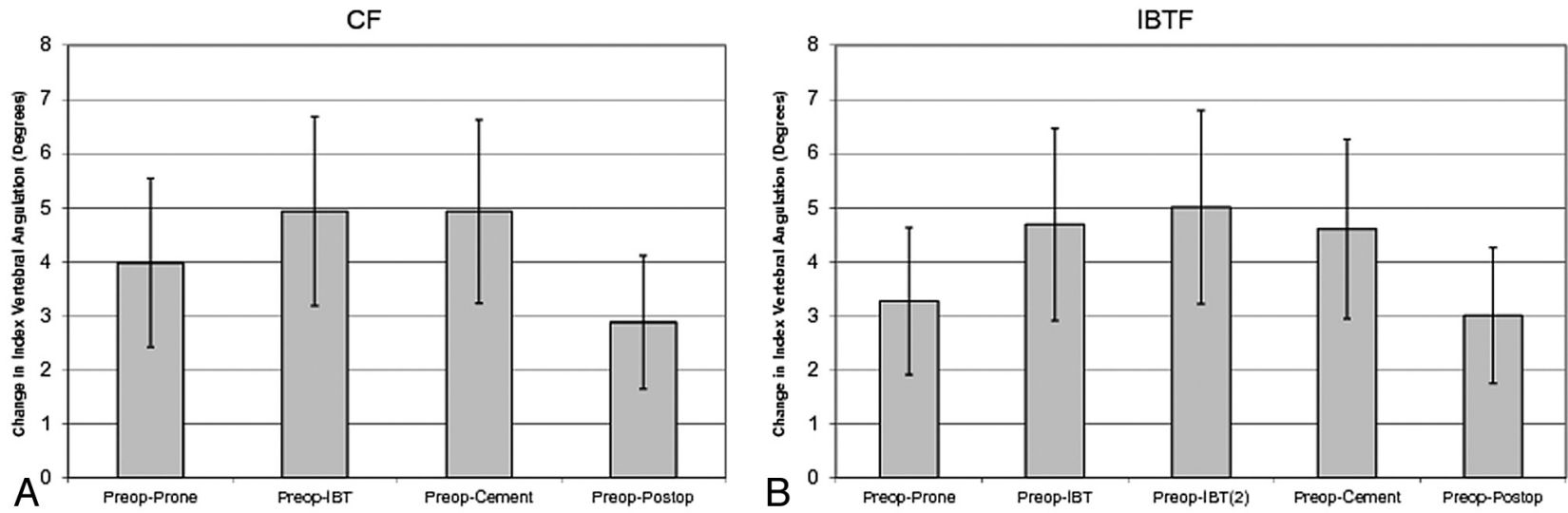

FIG 4. Index vertebral body kyphosis angle. CF $(A)$ and IBTF $(B)$ group means and $95 \%$ confidence intervals are shown for kyphotic angulation improvement (compared with preoperative) of index vertebral bodies measured as the angle between the inferior and superior endplates of index vertebrae after prone positioning (postural reduction), IBT inflation, cementation, and postoperative steps. Preoperative and postoperative assessments used standing lateral $x$-rays, and intraoperative assessments used lateral fluoroscopic images.

ment $(P=.4)$; similar results were found in the midvertebral measurements (Fig 3).

We also measured the vertebral body kyphosis angle for treated fractures (Fig 4). Compared with preoperative measurements, intraoperative postural reduction resulted, on average, in $3.98^{\circ}\left(95 \% \mathrm{CI}, 2.42^{\circ}-5.54^{\circ} ; P<.001\right)$ and $3.27^{\circ}\left(95 \% \mathrm{CI}, 1.90^{\circ}-\right.$ $4.63^{\circ}$; $P<.001$ ) of correction for the CF and IBTF groups (Fig 4 ); the additional benefit in amount of angulation attributed to the first IBT inflation was an additional $1.10^{\circ}\left(95 \%\right.$ CI, $0.51^{\circ}-1.68^{\circ}$; $P<.001)$ and $1.51^{\circ}\left(95 \% \mathrm{CI}, 0.70^{\circ}-2.33^{\circ} ; P<.001\right)$ of correction, respectively. The IBT contribution represented a $27 \%$ and $46 \%$ increase from the postural reduction measurements for CF and IBTF groups, but the results were not statistically different between groups $(P=.4)$. The final pre- to postoperative kyphosis correction was $2.88^{\circ}\left(95 \% \mathrm{CI}, 1.64^{\circ}-4.11^{\circ} ; P<.001\right)$ and $3.00^{\circ}$ (95\% CI, $1.74^{\circ}-4.25^{\circ} ; P<.001$ ) for the CF and IBTF groups, but differences were not statistically different between groups $(P=.9)$.

The local Cobb angle was measured for treated vertebrae. The postoperative correction of the local Cobb angle was $1.36^{\circ}(95 \%$ CI, $\left.0.33^{\circ}-2.38^{\circ} ; P=.010\right)$ and $1.87^{\circ}\left(95 \%\right.$ CI, $0.81^{\circ}-2.92^{\circ} ; P<$ $.001)$ for the CF and IBTF groups; the groups were not statistically significantly different $(P=.5)$.

\section{Mobile Fractures}

In evaluating the intraoperative contribution of postural reduction, IBT/curette use, and overall height restoration, improvement was better in each category for mobile fractures. Average anterior height gain attributed to postural reduction was $4.39 \mathrm{~mm}$ (95\% CI, 3.38-5.39 mm) for mobile fractures versus $1.40 \mathrm{~mm}$ (95\% CI, $0.68-2.11 \mathrm{~mm})$ for nonmobile ones $(P<.001$ for difference), and the additional gain attributed to IBT inflation was $1.57 \mathrm{~mm}$ (95\% CI, 1.08-2.06 mm) versus $0.91 \mathrm{~mm}$ (95\% CI, $0.50-1.31 \mathrm{~mm})$, respectively; the difference between mobile and nonmobile groups for IBT contribution was also statistically significant $(P=.043)$ and represents an approximate $35.8 \%$ and $65.0 \%$ increase over postural reduction, respectively. The final pre-/postoperative height change was better in the mobile fracture group (3.46 mm; 95\% CI, $2.58-4.34 \mathrm{~mm}$; $P<.001$ ) compared with nonmobile fractures $(1.52 \mathrm{~mm} ; 95 \% \mathrm{CI}, 0.84-2.21$ $\mathrm{mm} ; P<.001)$; this difference was statistically significant between the groups $(P<.001)$.

Figure 5 is an illustrative case example depicting angular-deformity correction for the treated fracture at all stages of the kyphoplasty procedure. The case example is from a 72-year-old female patient with a mobile L1 fracture. Placing the patient prone on the operating table resulted in an $8.9^{\circ}$ correction without bol- 

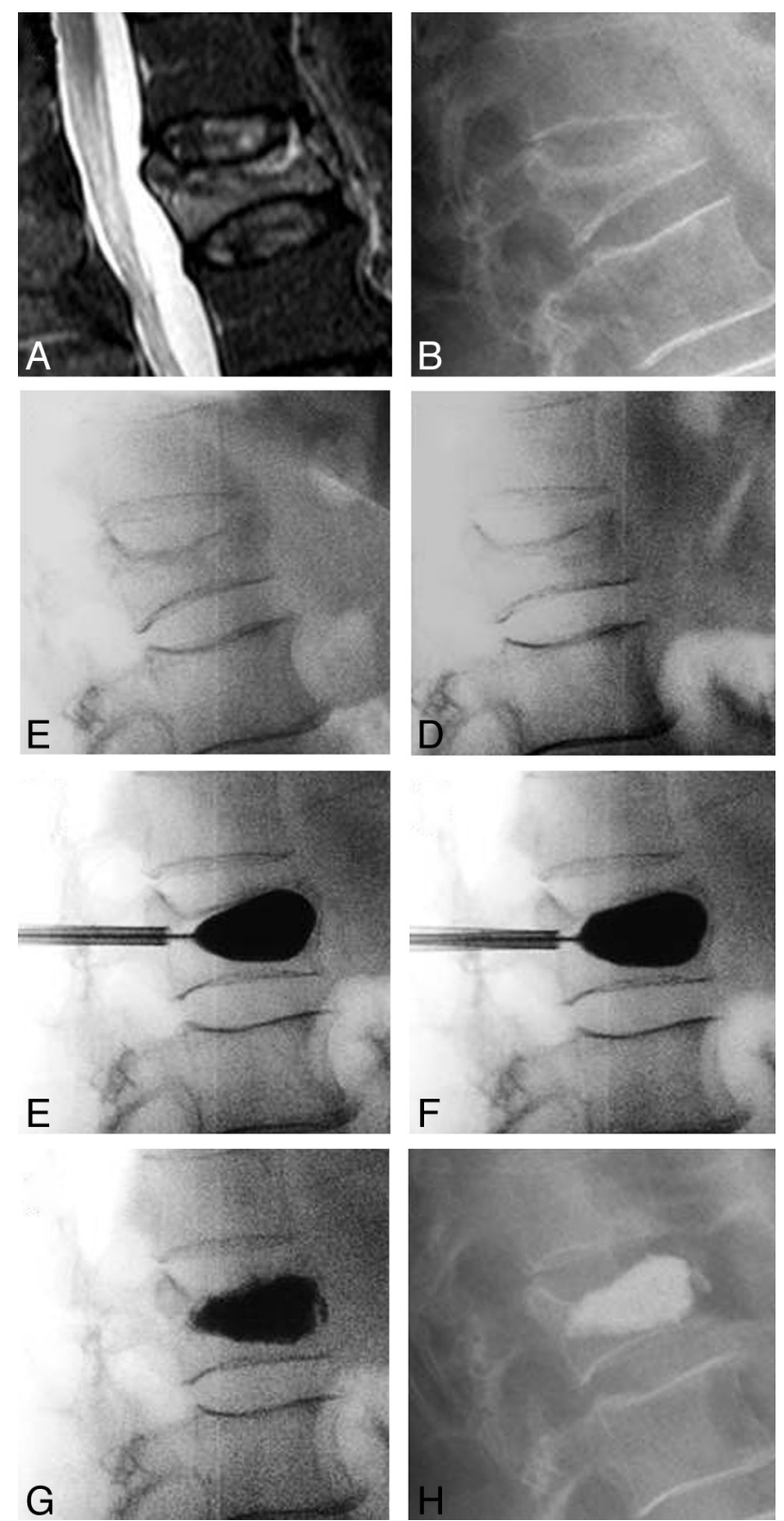

FIG 5. Case illustration of kyphosis correction for each step in the kyphoplasty procedure. A, Preoperative T2 short- $\tau$ inversion recovery MR imaging. $B$, Preoperative standing $\mathrm{x}$-ray. $C$, Intraoperative postural reduction without bolsters. $D$, Intraoperative postural reduction with a bolster. $E$, Intraoperative first balloon inflation. $F$, Intraoperative curette and second balloon inflation. $G$, Intraoperative cement placement. $H$, Postoperative standing $x$-ray.

sters and an additional degree of correction after placing chest and hip bolsters. The patient was randomized to the IBTF group, and the first balloon inflation was uniform, providing an additional $7^{\circ}$ of angular-deformity correction; the IBT inflation pressures were 120 PSI (bilateral) and were 4.0 (right) and 4.2 (left) $\mathrm{mL}$ in volume. After curette use and a second balloon inflation, there was a better inflation pattern and volume, with an additional degree of angular-deformity correction; for the second inflation, pressures were 106 (right) and 120 (left) PSI with an inflation volume of 5.0 $\mathrm{mL}$ for each side. The overall postoperative kyphosis correction of the fracture was $12.4^{\circ}$, and the local Cobb angle correction was $9.1^{\circ}$. In the overall cohort, 57 of 112 patients (51\%) had fractures
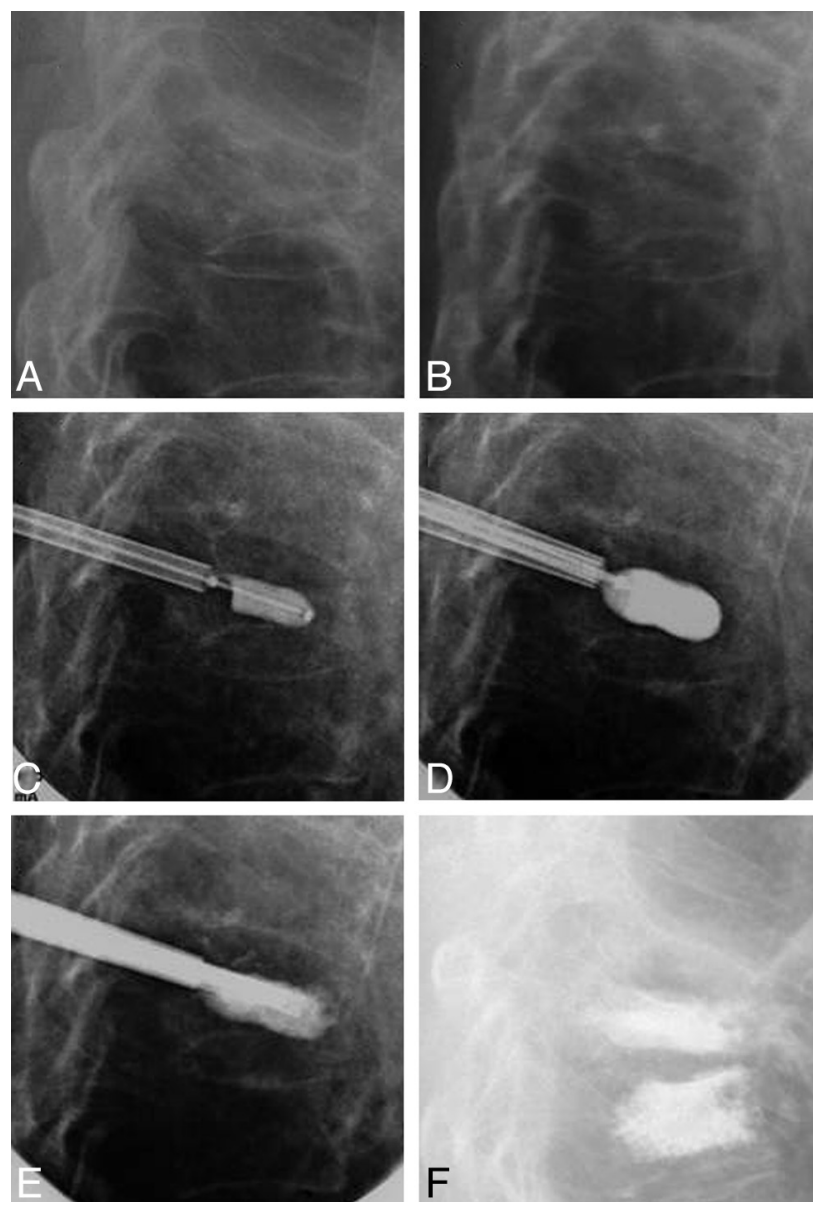

FIG 6. Case illustration of a nonmobile fracture. $A$, Preoperative standing $x$-ray. $B$, Intraoperative postural reduction with a bolster. $C$, Intraoperative first balloon inflation. $D$, Intraoperative curette and second balloon inflation. E, Intraoperative cement placement. F, Postoperative standing $x$-ray.

with dynamic mobility (Table 2); we performed analyses comparing mobile versus nonmobile fractures. The median age for mobile fractures was statistically significantly lower (3.0 weeks; IQR, 2.0-6.0 weeks) than nonmobile fractures (6.0 weeks; IQR, 3.010.0 weeks; $P=.042$ ).

Figure 6 is an illustrative case in which there was no postural reduction at $\mathrm{T} 7$; the 73 -year-old female patient was randomized to the IBTF group. The first balloon inflation was poor, had an irregular inflation pattern (119 [right] and 75 [left] PSI and 2.0 [right] and 1.0 [left] $\mathrm{mL}$ volume), and provided no angular-deformity correction. After curette use and a second balloon inflation, the result was a more uniform fill (119 [right] and 96 [left] PSI and $2.0 \mathrm{~mL}$, bilateral) with deformity correction. There was $2.4^{\circ}$ of correction overall at $\mathrm{T} 7$ in the standing postoperative measurement (the inferior T8 was treated within 30 days of initial treatment).

Figure 7 is an illustrative case in curette and balloon use; the 71year-old female patient had a nonmobile L1 fracture and was randomized to the IBTF group. The initial balloon inflation was poor and had an irregular inflation pattern (1.0 mL and 230 PSI, bilateral). After bilateral curette use and a second balloon inflation, the result was a more uniform fill (230 PSI, bilateral; and 2.5 [right] and $3.0 \mathrm{~mL}$ 

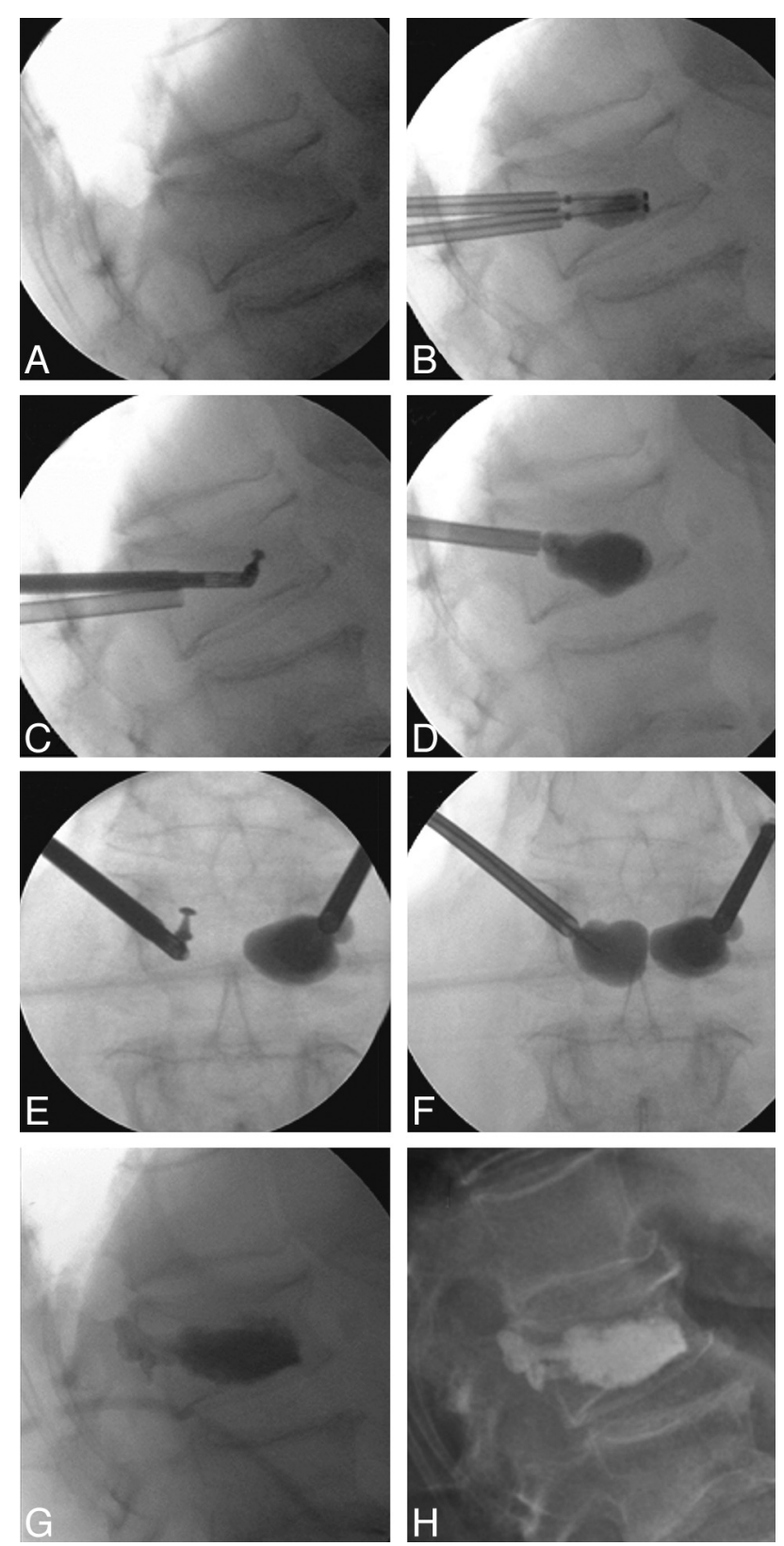

FIG 7. Case illustration of nonmobile fracture and use of curette. $A$, Intraoperative postural reduction with a bolster. $B$, Intraoperative first balloon inflation. $C$, Intraoperative curette usage (used bilaterally but image shows use only on 1 side). $D$, Intraoperative second balloon inflation. E, Anteroposterior (AP) film of C. F, AP film of D. G, Intraoperative cement placement. $H$, Postoperative standing $x$-ray.

[left]); however, the degree of vertebral body angulation correction was minimal overall $\left(0.2^{\circ}\right)$.

\section{Anesthesia Type}

We analyzed some parameters by general and local anesthesia groups. Fewer patients were treated with local anesthesia (Table 2); within the local anesthesia cohort, hospital duration was shorter (24.0 hours; IQR, 20.0-29.0 hours) compared with the general anesthesia group (72.0 hours; IQR, 24.0-96.0 hours; $P<.001$ ). More patients with local anesthesia $(16 / 19,84 \%)$ had nonmobile fractures compared with those with general anesthesia (39/93, 42\%; $P<.001)$ and had less fracture reduction in general (data not shown).

\section{Pain and Mobility}

Assessed by the 10-point numeric rating scale, the CF kyphoplasty group had a baseline back pain score of 7.7 points (95\% CI, 7.48.1 points), which was similar to that in the IBTF group (7.5 points; 95\% CI, 7.1-7.9 points). Both groups had statistically and clinically significant postoperative back pain relief (Fig 8). On average, the CF group had postoperative improvement to 3.0 points (95\% CI, $2.5-3.5$ points; $P<.001$ ) and the IBTF group improved to 3.3 points ( $95 \% \mathrm{CI}, 2.8-3.8$ points; $P<.001$ ). This represented $61 \%$ and $56 \%$ improvement for the CF and IBTF groups, which was not statistically significantly different $(P=$ .14 ); patients with mobile fractures had similar pain relief compared with patients with nonmobile fractures (data not shown). Concomitant with the pain reduction observed, more patients were able to freely ambulate postoperatively in both kyphoplasty groups (Fig 8).

\section{Safety}

No subject experienced an adverse event during surgery. Asymptomatic cement leakage occurred in $16 \%$ and $14 \%$ of vertebral bodies treated in the CF and IBTF groups (Table 3). The most common adverse events within 30 days were back pain (1 CF, 4 IBTF) and headache (2 CF, 1 IBTF). There was 1 nonserious device-related hematoma that occurred in the IBTF group (On-line Table 1). There were 5 nonserious adverse events that were possibly related to anesthesia (On-line Table 1), which included 2 cases of postoperative confusion and 1 case each of vomiting and arthralgia in the CF group and 1 case of headache in the IBTF group.

New vertebral fracture serious adverse events occurred in 2 patients, 1 in each group (On-line Table 2), both of which resulted in a subsequent surgical procedure. Three patients had serious adverse events that resulted in death (On-line Table 2). One patient with a lung infection did not respond to antibiotic therapy and died 35 days postoperatively. Another patient had pneumonia 4 days after surgery, which resulted in death; this patient had predisposing risk factors of cardiac insufficiency and previous cardiac valvuloplasty. A third patient died 6 days after surgery from septic shock; this patient presented with abdominal pain 4 days postkyphoplasty and was hospitalized with total colectomy and ileostomy. None of the serious adverse events, including those that resulted in death, were related to the device or procedure (On-line Table 2).

\section{DISCUSSION}

This study is the first that systematically used a curette in balloon kyphoplasty procedures documenting multiple outcomes. The results of this randomized trial comparing 2 different kyphoplasty techniques demonstrate statistically significant vertebral body height restoration and kyphosis correction in both treatment arms (CF and IBTF); the results also demonstrate that fracture mobility, fracture age, patient positioning, and IBT combined with curette use are important parameters that influence fracture reduction. Anesthesia type may be a factor influencing fracture mobility and vertebral body height restoration, but interpretation is limited by the small cohort and nonrandomized nature of this comparison. Both randomized treatment groups showed similar 

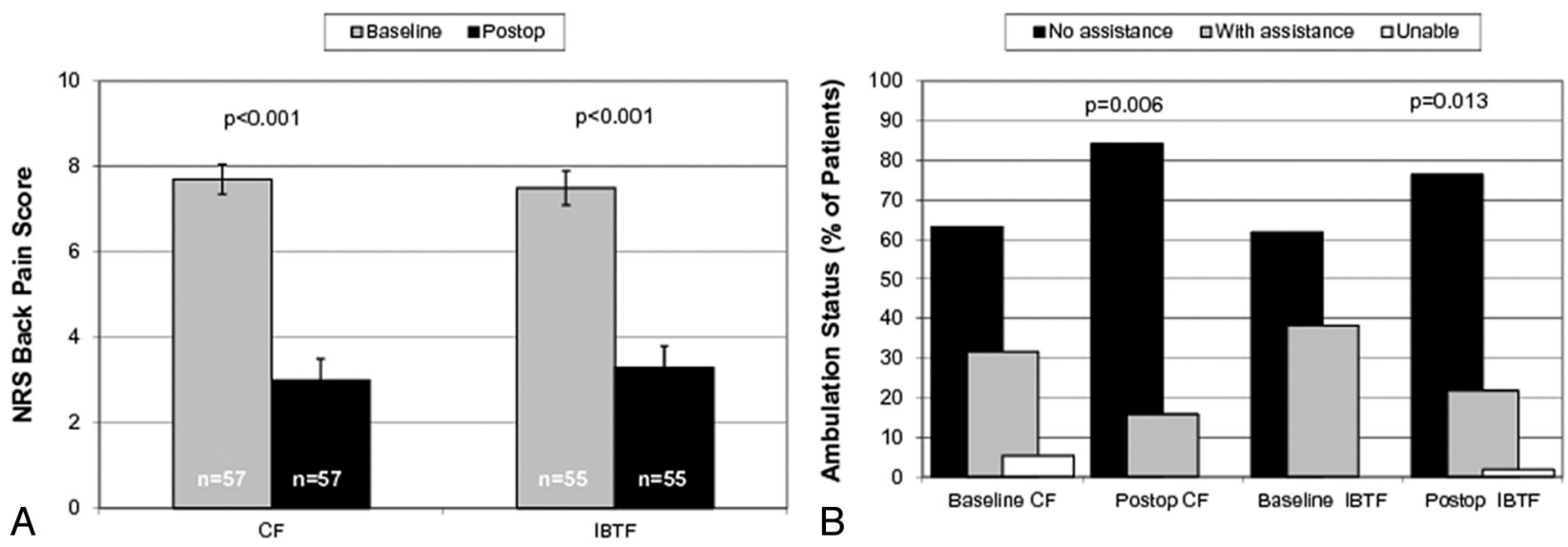

FIG 8. Postoperative back pain and ambulation. $A$, Group means and $95 \%$ confidence intervals are shown for the back pain numeric rating scale $(0-10)$ measured at baseline and discharge. Paired $t$ test $P$ values for comparison with baseline are shown for each group. $B$, Percentage of patients in each ambulation category is shown for baseline and at discharge for each group. Stuart-Maxwell $P$ values comparing postoperative status with baseline are shown for each kyphoplasty group.

vertebral body height restoration, pain and mobility, and safety outcomes. By qualitatively comparing the adverse event profile, cement extravasation rate, and the procedure and fluoroscopy duration that were observed in this trial with others, ${ }^{4,5,7,8,14,15}$ we found that the routine use of the curette should be considered safe.

Mounting evidence demonstrates that kyphoplasty and vertebroplasty provide better outcomes to nonsurgical management in randomized controlled studies. ${ }^{7,8,16-18}$ Although 2 randomized trials concluded that vertebroplasty was no different from a "sham" intervention for back pain, disability, and quality of life outcomes, ${ }^{19,20}$ these trials have been criticized due to several important limitations that make it hard to draw definitive conclusions. ${ }^{21,22}$ Kyphoplasty has not yet been compared with a sham intervention; this comparison would be a reasonable and definitive next step. However, kyphoplasty had better pain and EuroQol 5 dimensions quality-of-life outcomes compared with nonsurgical management throughout 2 years, ${ }^{7}$ an outcome not consistent with placebo effects. Currently, there is 1 small randomized trial that compared kyphoplasty with vertebroplasty; pain outcomes were similar but kyphoplasty provided statistically significantly better height-restoration outcomes. ${ }^{23} \mathrm{~A}$ few studies have demonstrated a possible connection between angulation and pulmonary function, ${ }^{24,25}$ but no definitive study has demonstrated a clinical benefit to height restoration.

Dynamic mobility of vertebral fractures has been investigated and described in the published literature. ${ }^{26,27} \mathrm{McKiernan}$ et $\mathrm{al}^{27}$ in a prospective case series of patients with vertebroplasty estimated that $35 \%$ of fractures had dynamic mobility, and these authors reported improvement of kyphosis in the subset of patients with mobile fractures. In our series, 50\% of patients (and fractures treated) had mobile fractures; overall kyphosis correction improved from $-15.2^{\circ}$ to $-10.7^{\circ}$, an approximate $30 \%$ improvement for mobile fractures treated in this study with BKP. Improvement in nonmobile fracture was approximately half as much at $14 \%$ improvement. In our series, mobile fractures, not surprisingly, were younger fractures.
Postural reduction and additional IBT contribution have also been documented in several studies. ${ }^{6,28}$ In our study, for both treatment groups, the intraoperative contribution of postural reduction was statistically significant and substantial (Figs 3 and 4); the intraoperative IBT contribution was also statistically significant and represented a $27 \%-46 \%$ increase over postural reduction. This additional correction of angulation (and vertebral body height) by the IBT/curette was maintained after IBT removal and subsequent cement placement. It is difficult to translate intraoperative contributions to the final results because the spine is unloaded intraoperatively but loaded in baseline and postoperative assessments. Overall, the final kyphosis correction/vertebral body height restoration in our study was lesser to some extent compared with other results such as those by Voggenreiter ${ }^{6}$; this finding may be due to the multicenter nature of our study, larger sample size, and the independent radiographic core lab assessments, which minimize reader bias. It will be of interest in future studies to understand deformity-correction outcomes with new inflatable bone tamp technologies that are made of less compliant materials.

Kyphoplasty with curette usage was found to be safe for the treatment of VCFs in patients with osteoporosis. Both treatment groups had a similar safety profile; as shown in On-line Tables 1 and 2 , medical adverse events were similar between the 2 groups during the 1-month period, as randomized. There was 1 nonserious device-related hematoma that occurred in the IBTF group. Several other nonserious adverse events were attributed to the effects of anesthesia. No serious adverse event was device-related. Asymptomatic cement extravasation occurred in 15\% of treated vertebral bodies overall. The safety profile and cement leakage are similar to those in several other studies in which the curette was not routinely used, suggesting that routine use of the curette does not alter the safety profile of kyphoplasty. $4,7,8$

A limitation of this study is that it was not blinded; though ours was primarily a radiographic study, the core lab was blinded to treatment assignment. Although some may consider the short follow-up a limitation, the study was purposefully designed as 
such to focus on intraoperative assessments for determining height restoration. A limitation may be perceived by the difficulty in standardizing the exact use of the curette due to variations in anatomy and the bone environment; on the contrary, most importantly, the variability of use adds to the generalizability of the study because it represents the reality of curette use in clinical practice. Furthermore, the contribution of the curette itself is difficult to ascertain because both treatment arms used the curette. Nonetheless, the strengths are the randomized multicenter trial design and the multiple independent radiographic assessments that included several measurements within the intraoperative time frame.

Both treatment groups (CF and IBTF) showed statistically significant improvements in anterior and mid-vertebral body height, kyphosis correction, pain improvement, and ambulation status, consistent with several other kyphoplasty studies. ${ }^{4-7}$ However, we were not able to demonstrate statistically significant differences between treatments groups, though there may have been a trend for better radiographic results in the IBTF group. It is also difficult to ascertain the contribution of the curette itself because both treatment groups used the curette; however, when we compared the 2 groups at the initial balloon inflation step (preoperative IBT in Figs 3 and 4), there was little difference between groups. This finding provides some information because in the CF group, the curette was used just before IBT inflation and in the IBTF group, the curette was not yet used in the first IBT step. Therefore, in general, we do not think it is necessary to use the curette in every kyphoplasty case. Physicians may expect increased fluoroscopy time or procedure duration with additional tool use; however, we have demonstrated that curette use can be performed safely and, in comparison with other BKP studies, does not seem to increase overall operation time or fluoroscopy time. ${ }^{14,15}$ We have demonstrated, in several individual cases, that after initial IBT placement, the use of the curette can help better position the IBT and provide better inflation patterns on the second or third IBT inflations; this outcome is likely in sclerotic or harder bone environments and older fractures. In our experience, preoperative films with increased attenuation in the fractured vertebral body or resistance in introducing the needle may be indicative of hard/sclerotic bone; in these cases, the use of the curette may be warranted before balloon inflation to help direct the balloon tamps. However, most often the initial balloon inflation is most telling. Small balloon volumes at high pressures or irregular balloon shapes indicate the presence of hard/sclerotic bone; therefore, decisions regarding curette use are made intraoperatively. We, therefore, recommend the use of the IBT-first approach and then determining the need for curette use in kyphoplasty procedures. Anatomy correction is an important consideration in fracture management, and the treating physician should consider all parameters to achieve this end point in vertebral augmentation procedures.

\section{CONCLUSIONS}

Two different techniques with BKP and curette use resulted in significant vertebral body height restoration, kyphotic deformity correction, and pain improvements. Procedure and adverse event data demonstrated safe curette use in conjunction with balloon kyphoplasty procedures. Fracture mobility, fracture age, patient positioning (bolstering), IBT and curette use, and possibly anesthesia type are important parameters that may influence fracture reduction. Treating physicians should consider all of these parameters in achieving maximal anatomy correction when performing vertebral augmentation procedures.

\section{ACKNOWLEDGMENTS}

The authors and study investigators are indebted to the patients who consented to participate in the SCORE trial and to all participating staff at the investigational centers. We thank Talat Ashraf, $\mathrm{MD}$, and $\mathrm{Li} \mathrm{Ni}, \mathrm{PhD}$, (Medtronic Spine) for their contributions to medical monitoring and statistical analysis, respectively.

Disclosures: Leonard Bastian: RELATED: Grant: * Consulting Fee or Honorarium, Support for Travel to Meetings for the Study or Other Purposes, Fees for Participation in Review Activities such as Data Monitoring Boards, Statistical Analysis, End Point Committees, and the Like, Payment for Writing or Reviewing the Manuscript: Medtronic Spine LLC, UNRELATED: Board Membership, Consultancy, Expert Testimony, Payment for Lectures (including service on Speakers Bureaus, Payment for Manuscript Preparation: Medtronic Spine LLC.). Frederic Schils—RELATED: Fees for Participation in Review Activities such as Data Monitoring Boards, Statistical Analysis, Endpoint Committees, and the Like: Medtronic, UNRELATED: Board Membership: Medtronic, Consultancy: Medtronic; Payment for Lectures (including service on Speakers Bureaus): Medtronic, DePuy. John B. Tillman-RELATED: Other: Medtronic Spine, Comments: As an employee of Medtronic during the period of this work, I received salary and owned stock and stock options in Medtronic, UNRELATED: Employee: Medtronic Spine, Comments: Clinical Program Director, Stock/ Stock Options: Medtronic. George Fueredi-RELATED: Fees for Participation in Review Activities such as Data Monitoring Boards, Statistical Analysis, Endpoint Committees, and the Like: Medtronic, ${ }^{*}$ Comments: As chair of the publication committee at my institution, Aurora Healthcare, I received a fee for my services with regard to attending publication committee meetings. No fee was paid for writing the publication, UNRELATED: Consultancy: Medtronic, ${ }^{*}$ Comments: My institution receives compensation for my services to Medtronic for services with regard to product development, Expert Testimony: various attorney firms, Comments: I provide expert testimony for various defense and plaintiff attorneys on a variety of medical legal issues, primarily as they relate to interventional radiology cases, Payment for Lectures (including service on Speakers Bureaus): Medtronic, ${ }^{*}$ Comments: I am part of the Medtronic Kyphon Speakers Bureau and provide services to train physicians in balloon kyphoplasty. *Money paid to the institution.

\section{APPENDIX \\ SCORE Investigators}

Belgium (35 enrolled patients)

F. Schils, Liège

K. De Smedt, Wilrijk

Germany (50 enrolled patients)

G. Voggenreiter, Eichstätt

M. Markmiller, Kempten

L. Bastian, Leverkusen

H.C. Harzmann, München

B. Böhm, Nürnberg

M. Bierschneider, Regensburg

U. Laupichler, Schwandorf

United States (35 enrolled patients)

G. Fueredi, Burlington, Wisconsin

J. Small, Temple Terrace, Florida

\section{REFERENCES}

1. Silverman $S$. The clinical consequences of vertebral compression fracture. Bone 1992;13:S27-31

2. Cooper C, Atkinson EJ, O’Fallon WM, et al. Incidence of clinically 
diagnosed vertebral fractures: a population-based study in Rochester, Minnesota, 1985-1989. J Bone Miner Res 1992;7:221-27

3. Phillips FM, Todd Wetzel F, Lieberman I, et al. An in vivo comparison of the potential for extravertebral cement leak after vertebroplasty and kyphoplasty. Spine 2002;27:2173-78, discussion $2178-79$

4. Garfin SR, Buckley RA, Ledlie J. Balloon kyphoplasty for symptomatic vertebral body compression fractures results in rapid, significant, and sustained improvements in back pain, function, and quality of life for elderly patients. Spine (Phila Pa 1976) 2006;31:2213-20

5. Berenson J, Pflugmacher R, Jarzem P, et al. Balloon kyphoplasty versus non-surgical fracture management for treatment of painful vertebral body compression fractures in patients with cancer: a multicentre, randomised controlled trial. Lancet Oncol 2011;12: $225-35$

6. Voggenreiter G. Balloon kyphoplasty is effective in deformity correction of osteoporotic vertebral compression fractures. Spine (Phila Pa 1976) 2005;30:2806-12

7. Boonen S, Van Meirhaeghe J, Bastian L, et al. Balloon kyphoplasty for the treatment of acute vertebral compression fractures: 2-year results from a randomized trial. J Bone Miner Res 2011;26:1627-37

8. Wardlaw D, Cummings SR, Van Meirhaeghe J, et al. Efficacy and safety of balloon kyphoplasty compared with non-surgical care for vertebral compression fracture (FREE): a randomised controlled trial. Lancet 2009;373:1016-24

9. Lindsay R, Silverman SL, Cooper C, et al. Risk of new vertebral fracture in the year following a fracture. JAMA 2001;285:320-23

10. Garfin SR, Yuan HA, Reiley MA. New technologies in spine: kyphoplasty and vertebroplasty for the treatment of painful osteoporotic compression fractures. Spine 2001;26:1511-15

11. Eastell R, Cedel SL, Wahner HW, et al. Classification of vertebral fractures. J Bone Miner Res 1991;6:207-15

12. Farrar JT, Young JP Jr, LaMoreaux L, et al. Clinical importance of changes in chronic pain intensity measured on an 11-point numerical pain rating scale. Pain 2001;94:149-58

13. MedDRA Data Retrieval and Presentation: Points to Consider. ICH-Endorsed Guide for MedDRA Users on Data Output. 2012. Available at: http://www.ich.org/fileadmin/Public_Web_Site/ICH_ Products/MedDRA/MedDRA_Documents/MedDRA_Date_Retrieval _and_Presentation/Release_3.3_based_on_v.15.0/DataRetrieval_R3.3_ march2012.pdf

14. Mroz TE, Yamashita T, Davros WJ, et al. Radiation exposure to the surgeon and the patient during kyphoplasty. J Spinal Disord Tech 2008;21:96-100
15. Ortiz AO, Natarajan V, Gregorius DR, et al. Significantly reduced radiation exposure to operators during kyphoplasty and vertebroplasty procedures: methods and techniques. AJNR Am J Neuroradiol 2006;27:989-94

16. Farrokhi MR, Alibai E, Maghami Z. Randomized controlled trial of percutaneous vertebroplasty versus optimal medical management for the relief of pain and disability in acute osteoporotic vertebral compression fractures. J Neurosurg Spine 2011;14:561-69

17. Klazen CA, Lohle PN, de Vries J, et al. Vertebroplasty versus conservative treatment in acute osteoporotic vertebral compression fractures (Vertos II): an open-label randomised trial. Lancet 2010;376:1085-92

18. Papanastassiou ID, Phillips FM, Van Meirhaeghe J, et al. Comparing effects of kyphoplasty, vertebroplasty, and non-surgical management in a systematic review of randomized and non-randomized controlled studies. Eur Spine J 2012 Apr 29. [Epub ahead of print]

19. Kallmes DF, Comstock BA, Heagerty PJ, et al. A randomized trial of vertebroplasty for osteoporotic spinal fractures. $N$ Engl J Med 2009;361:569-79

20. Buchbinder R, Osborne RH, Ebeling PR, et al. A randomized trial of vertebroplasty for painful osteoporotic vertebral fractures. $N \mathrm{Engl}$ J Med 2009;361:557-68

21. Bono CM, Heggeness M, Mick C, et al. North American Spine Society: Newly released vertebroplasty randomized controlled trials: a tale of two trials. Spine J 2010;10:238-40

22. Clark W, Lyon S, Burnes J, et al. Trials of vertebroplasty for vertebral fractures. N Engl J Med 2009;361:2097-100, author reply 2099-100

23. Liu JT, Liao WJ, Tan WC, et al. Balloon kyphoplasty versus vertebroplasty for treatment of osteoporotic vertebral compression fracture: a prospective, comparative, and randomized clinical study. Osteoporos Int 2010;21:359-64

24. Yang HL, Zhao L, Liu J, et al. Changes of pulmonary function for patients with osteoporotic vertebral compression fractures after kyphoplasty. J Spinal Disord Tech 2007;20:221-25

25. Dong R, Chen L, Gu Y, et al. Improvement in respiratory function after vertebroplasty and kyphoplasty. Int Orthop 2009;33:1689-94

26. Chin DK, Kim YS, Cho YE, et al. Efficacy of postural reduction in osteoporotic vertebral compression fractures followed by percutaneous vertebroplasty. Neurosurgery 2006;58:695-700, discussion 695-700

27. McKiernan F, Jensen R, Faciszewski T. The dynamic mobility of vertebral compression fractures. J Bone Miner Res 2003;18:24-29

28. Shindle MK, Gardner MJ, Koob J, et al. Vertebral height restoration in osteoporotic compression fractures: kyphoplasty balloon tamp is superior to postural correction alone. Osteoporos Int 2006;17: 1815-19 